\title{
NOTICIARIO
}

\section{Noticias literarias de Francia}

T27.7. EDERICO Lefèvre ha consagrado el prestigio de Andrés Maurois, que cuenla pocos años pero que es ya bastante poderoso y extenso. En efecto, ha escrito un libro acerca de Maurois que contiene todo lo que puede pedir el lector curioso para informarse sobre el autor de la .Vida de Shelleys. dada a conocer al público de Afenea por Hernán Diaz Arriela el año antepasado.

El libro de Lefèvre contiene primeramenle una parle biográfica, que nos ofrece bastantes detalles sobre Maurois. Nacido en 1885, en Elbeuf, de una lamilia de industriales, hizo sus estudios en Ruán. En el liceo de esta ciudad tuvo buenos profesores que le hicieron entrar en las letras y en la filosolia a una edad en que muchos niños piensan sölo en jugar y pasar el tiempo. Chartier, admirador de Balzac y de Stendhal, fué uno de los más destacados maestros de Maurois y de él conserva éste un recuerdo gralisimo.

Terminados los estudios, abandonado a sus propias fuerzas por su familia, Andrés Maurois se dedicó a la industria. Durante diez años, en el pueblo natal, estuvo a cargo de una usina, lo que no le impidió conservar sus anhelos y ambiciones de escritor. En este tiempo hace su primer volumen, una colección de cuentos escritos entre los dieciseis y los veinte años. Cuando corregia las pruebas, Maurois siente que esa obra no merece ser impresa y hace distribuir la composición. Mucho tiempo ha pasado desde aquella pequeña aventura. Ahora el aulor 
conserva, además del recuerdo, diez pruebas de aquellas páginas de juventud.

Durante sus años de industrial Maurois leyó muchos libros. tanto de literatura como de filosofia. Buen lector, hace extractos. guarda citas y referencias y en breves nolas explaya su propio pensamiento. Más tarde el escritor toma parte en la guerra, y en su cartera va anolando cuidadosamente lo que ve y oye en las trincheras. En 1918 Grasset publica el primer ensayo novelesco de Maurois, titulado sLos silencios del coronel Bramble, relato de la guerra junto a los ingleses.

1918 puede ser considerado como el comienzo de la carrera literaria de este escritor. Ocho años han pasado desde entonces y su lista de obras cuenta ya con olros tantos libros. de los cuales cada uno ha sido un éxito en su género. Ariel - la vida de Shelleys es el más conocido, el más divulgado. el que atrajo hacia Maurois la atención de muchos miles de lectores de lodo el mundo.

El libro de Lefêvre nos ofrece. después de las notas biográficas y bibliográficas aludidas, opiniones de Maurois acerca de numerosos puntos literarios, artísticos y críticos. En ellas el autor no teme decirnos claramente cuál es su apreciación de la obra de muchos escritores contemporáneos. Los hermanos Tharaud, Péguy, Bernanos, Daudet, Freud son los objetos de varias conversaciones entre Lefèvre y Maurois. Pero no es sólo eso. Maurois, hombre de pensamiento, no vale menos que Maurois novelista. Su explicación de las vicisitudes de los franceses en lo que va corrido del siglo tiene el mérito de un sistema moral e histórico. esbozado sólo pero no por eso menos valioso.

Tal es, en breve sintesis, el contenido del libro de Lefèvre, integral revelación de Andrés Maurois, novelista y ensayista en quien Francia cuenta con uno de sus más sólidos prestigios.

Marcelle Auclair, colaboradora de Afenea, ha contraido ma- 
trimonio hace poco en Francia. Su marido es un escritor, Jean Prévost, que tiene ya una buena hoja de servicios en la literafura francesa.

Prévost es autor de un volumen de ensayos titulado .Plaisirs des Sporls, y publicado por la Nouvelie Revue Française en 1925. Es un alarde de fuerza dueña de sĩ, bien dispuesta y conducida de manera reverente. Prévost ama los deportes por el factor de belleza y de bienestar que traen a la vida. Los ve desprovistos de brutalidad. llenos de armonía, dar al cuerpo la plenilud de su desarrollo y cierto refinamiento distinguido. Para él un cuerpo bien adiestrado es el mejor compañero de un espiritu culto al cual no fueran ajenos ni el placer de pensar ni la seducción de los sueños. Escrito, además, con mucha conciencia del lenguaje y con toda la precisión lécnica que el tema exige, este libro ha sido considerado dentro de la stradición, francesa. Eso quiere decir que es claro, preciso. lleno de distinción y de elegancia. No es poco decir.

El sentimiento páriótico no decrece en Francia, sino que por lo contrario siempre algún motivo o prelexto sirve para reactivarlo. Los últimos periódicos literarios franceses nos traen anuncios delallados de una obra monumental tilulada. Anthologie des écrivains morts à la guerres. No hemos exagerado al decir que esła obra es monumental. Sabemos, por ejemplo, que constará de cinco grandes volúmenes en los cuales se encontrarán trabajos de cuatrocientos selenta escritores franceses muertos en la guerra, de veintiün hombres muertos después del armisticio. de cuarenta muertos por enfermedades contraidas en las trincheras, de trece escritores belgas muertos y de dieciocho escritores extranjeros, enrolados voluntariamente en las filas francesas. Total. quinientos sesenta y dos escrilores...

No nos preocupemos de establecer por qué es tan alto este número. Bien sabemos ya que en Francia los escritores abundan y que sobre lodo en los grupos juveniles que lueron los 
que más certeramente diezmó la guerra, el número de aficionados a la literatura necesariamente tenia que ser grande. Digamos algo más sobre la obra misma. La publicación estará patrocinada por la Asociación de Escritores Combatientes y dirigida por Thierry Sandre. El tomo primero llevará introducciones de Henry de Jouvenel y León Berard, Ministros de Instrucción Pública y Bellas Artes, respectivamente. El tomo segundo, de Georges Lecomte, Presidente de la Sociedad de Escritores; el tercero, de Robert de Flers, Presidente de la Sociedad de Autores y Compositores dramáticos; el cuarto, de René Doumic. Secrelario perpetuo de la Academia Francesa, y el quinto. de Gustave Geffroy, ex-Presidente de la Academia Goncourt. No puede negarse que la obra tiene un carácter netamente oficial. afirmado por los numerosos colaboradores vivos. Entre estos últimos no podemos menos de citar a Bourget, Carco, Le Cardonnel, Mauclair, Massis, Maspero, Reinach, Vaudoyer. efc.

Se augura un éxito clamoroso a esta Anlologia que volverá a presentar de cuerpo entero la magnitud de la catástrofe que la guerra significó para la inteligencia y la cultura francesa.

Una obra misteriosa ha comenzado a circular-en muy pocas manos, por cierlo-en Francia y en algunos países europeos. Se titula .Les sept pechés capitaux, y contiene, como su nombre lo indica, siete capitulos dedicados a cada uno de los pecados capitales.

Jean Giraudoux escribe sobre el orgullo, el más inocente de los pecados. Sin embargo, él lo califica como el más grave de todos y acaso como el único pecado. Luego Paul Morand habla sobre la avaricia en pequeñas máximas que tienen el sabor de los viejos moralistas de la edad de oro. Posiblemente es este uno de los capílulos que más ha complacido a la crílica. De la envidia se ocupa Andrés Salmón; de la lujuria, Pierre Mac Orlan. Sobre la gula escribe Max Jacob, en forma anecdótica y animadísima. Joseph Kessel para escribir sobre la 
pereza traslada al lector a Rusia, país en el cual, según él, tal pecado adquiere contornos especiales. Jacques de Lacretelle, en fin, escribe sobre la cólera un relato vivo que destaca fuerlemente sobre el conjunlo.

Tal es la obra misteriosa, que contiene ricas aguafuertes de Max Chagall. adapladas vigorosamenle al texto. Hemos dicho también que el libro ha circulado en pocas manos, por una razón muy simple: su alto precio. Dieciseis ejemplares en papel Japón y cuarenta y cuatro en Holanda se han editado a mil ochocientos y mil francos cada uno, respectivamente. La edición corriente consta de doscientos cuarenta ejemplares a trescientos francos cada uno. Nos parece esto razón de sobra para que -Les sept pechés capilaux, no se halle en nuestras librerias.

OMEGA. 